\title{
Improved Survival of HER2-Positive Metastatic Breast Cancer in Routine Care
}

\author{
Rudolf Weide ${ }^{1}$, Stefan Feiten ${ }^{2}$, Vera Friesenhahn ${ }^{2}$, Jochen Heymanns ${ }^{1}$, Kristina Kleboth ${ }^{2}$, Ulrike Mergenthaler ${ }^{2}$, \\ Jörg Thomalla ${ }^{1}$, Christoph van Roye ${ }^{1} \&$ Hubert Köppler ${ }^{1}$ \\ ${ }^{1}$ Praxisklinik für Hämatologie und Onkologie, Neversstr. 5, Koblenz 56068, Germany \\ ${ }^{2}$ Institut für Versorgungsforschung in der Onkologie, Neversstr. 5, Koblenz 56068, Germany \\ Correspondence: Rudolf Weide, Praxisklinik für Hämatologie und Onkologie, Koblenz, Germany. Tel: \\ 49-(0)261-9215-69323. E-mail: weide@onkologie-koblenz.de
}

Received: October 30, 2012 Accepted: November 18, 2012 Online Published: December 10, 2012

doi:10.5539/cco.v2n1p17 URL: http://dx.doi.org/10.5539/cco.v2n1p17

This study was supported through a restricted grant by Roche Pharma, Grenzach-Wyhlen, Germany. The sponsoring by Roche had no influence on data analysis, conclusions and manuscript writing

\begin{abstract}
Purpose: Targeted therapy directed against HER2 has improved the outcome of patients with HER2-positive metastatic breast cancer in prospective clinical trials. No data are available how anti-HER2-therapy has influenced survival of unselected patients with HER2-positive metastatic breast cancer who receive treatment in routine care. Methods: Data of 118 subsequent patients with HER2-positive metastatic breast cancer who were treated in a community-based oncology group practice between 1995 and 2010 were analyzed retrospectively. Results: Median age at initial diagnosis of metastasis was 58 years (33-92). Twenty-two percent were metastasized at diagnosis of breast cancer, seventy-eight percent developed metastases in the course of the disease. Distribution of metastatic sites at initial diagnosis of metastasis was: $23 \%$ bone, $58 \%$ visceral, $5 \%$ CNS, $10 \%$ lymph nodes, $4 \%$ other. Hormone receptor was positive in $68 \%$ and negative in $31 \%$. Palliative treatment consisted of antihormonal therapy in 56\%, chemotherapy in $90 \%$ and radiotherapy in $50 \%$. Seventy-five percent received anti-HER2-therapy consisting of trastuzumab in $80 \%$ and lapatinib in 1\%, 19\% received trastuzumab + lapatinib sequentially. Twenty-five percent received no anti-HER2-therapy. Median overall survival since initial diagnosis of metastasis was 34 months $(0-277+)$. Conclusion: It could be shown that, compared to historical controls, targeted therapy against HER2 prolongs overall survival of patients with HER2-positive metastatic breast cancer who receive treatment in routine care.
\end{abstract}

Keywords: HER2, breast cancer, trastuzumab, lapatinib, routine care

\section{Introducation}

HER2 is a $185 \mathrm{kd}$ transmembrane tyrosine kinase which is overexpressed in $15-18 \%$ of primary breast cancer cases (Slamon et al., 1987; Dendukuri, Khetani, McIsaac, \& Brophy, 2007). HER2 belongs to a family of tyrosine kinases (HER1, HER2, HER3, HER4). Homodimerization of HER2 with itself or heterodimerization with HER1, HER3 or HER4 activates the intracellular tyrosine kinase leading to the stimulation of cell proliferation via the RAS/MAPK-pathway, inhibition of apoptosis via the PI3K/AKT/mTOR-pathway and promotion of angiogenesis due to VEGF-stimulation (Hudis, 2007). It has been demonstrated that HER2-positve breast cancer cells show increased motility and invasiveness. Overexpression of HER2 has been shown to be a strong negative prognostic factor in breast cancer leading to early visceral and brain metastases (Slamon et al., 1987). HER2-positive metastatic breast cancer has an inferior outcome compared to HER2-negative disease with a median overall survival of 18-20 months (Smith, 2001; Slamon et al., 2001). Trastuzumab is a humanized monoclonal antibody directed against the extracellular domain of HER2. Binding of trastuzumab to HER2 inhibits HER2-dimerization and HER2-activation (Hudis, 2007). Additionally trastuzumab induces antibody dependent cell mediated cytotoxicity (ADCC) by attracting natural killer cells (NK cells) and macrophages which themselves are able to kill trastuzumab-coated HER2-positive tumour cells (Hudis, 2007; Clynes, Towers, Presta, \& Ravetch, 2000). Thus trastuzumab is able to kill breast cancer cells by the inhibition of the cell 
communication between cell surface and nucleus. Additionally trastuzumab directs the immune system of the patient against breast cancer cells which leads to killing of breast cancer cells by natural killer cells and macrophages of the immune system.

Trastuzumab-monotherapy has been shown to be effective in first line, and further lines of therapy in patients with HER2-positive metastatic breast cancer (Baselga et al., 1996; Cobleigh et al., 1999; Vogel et al., 2002). Within the pivotal trial first line therapy with trastuzumab prolonged overall survival in combination with anthracycline- or paclitaxel-chemotherapy from 20.3 to 25.1 months compared to chemotherapy alone in HER2-positive metastatic breast cancer (Slamon et al., 2001). Lapatinib is a dual HER1 and HER2 tyrosine kinase inhibitor, which in combination with capecitabine has shown activity in trastuzumab-refractory HER2-positive metastatic breast cancer and brain metastases (Geyer et al., 2006; Lin et al., 2008). To date trastuzumab-monotherapy, immunochemotherapy with trastuzumab, aromatase inhibitor plus trastuzumab in hormone receptor-positive tumours and lapatinib-capecitabine in trastuzumab-refractory disease and brain metastases respectively are all considered standard treatment options in HER2-positive metastatic breast cancer. Prospective clinical trials have demonstrated a prolongation of overall survival by adding trastuzumab to chemotherapy (Smith, 2001; Slamon et al., 2001; Marty et al., 2005).

On the other hand it is known that less than $2 \%$ of patients with metastatic breast cancer, who are older than 60 years, are treated within prospective clinical trials (American College of Physicians, 1999). Data from prospective clinical trials are not transferrable into routine care because a significant percentage of patients is excluded from these trials, for example very old patients, patients with brain metastasis, impaired organ function, significant comorbidities, certain pretherapies or a low performance status. No data are available so far how anti-HER2-therapy might influence overall survival in unselected patients with HER2-positive breast cancer who receive treatment outside clinical trials in routine care. This was the reason for us to ask the question whether anti-HER2-therapy leads to a prolongation of life in unselected patients with metastatic HER2-positive breast cancer who received routine care treatment in a community based oncology practice in Germany?

\section{Patients and Methods}

This was a retrospective study in unselected female patients with HER2-positive metastatic breast cancer who received routine treatment in an oncology group practice in Germany between 06/1995-12/2010. From the time of first diagnosis of metastatic disease until death or the end of observation within this study all patients were treated on an outpatient basis. Patients stayed in their private environment, mostly within their families and received support from relatives and friends. Within the oncology group practice continuity of care was assured by a constant patient-oncologist-relationship. Apart from relatives and friends patients received psychosocial support from their oncologist, the oncology team, general practitioners, gynaecologists, psychologists, social workers and clergy.

All patients gave written informed consent concerning data analysis and data distribution - since it was a retrospective analysis and the patients have agreed no ethical approval was necessary. Participants had to have at least one distant metastasis at the time of diagnosis of metastatic disease. HER2-positivity was defined as 2+ or $3+$ overexpression in immunohistochemistry by DAKO HercepTest; in case of 2+, additional overexpression by fluorescence in situ hybridization (FISH) or chromatographic in situ hybridization (CISH) was required. HER2 was evaluated at the time of metastasis and, if not available, at the time of initial diagnosis of breast cancer. All relevant patient data were extracted from patient files and transferred into a database by experienced study nurses. Statistical analyses using SPSS 19 were conducted by a research associate who was supported by an oncologist. Missing data were retrieved from departments of pathology, gynaecology, radiology, radiotherapy, from community based gynaecologists, general practitioners, patients and relatives. At the time of first breast cancer diagnosis the following data were evaluated: age, menopausal status, stage according to TNM $\left(7^{\text {th }}\right.$ edition, 2010), HER2-overexpression, ER/PR-status, grading, histological type, type of operation, type and duration of adjuvant therapy. At the time of diagnosis of metastatic disease: age, menopausal status, time between first breast cancer diagnosis and metastasis (DFS), site of metastasis, number of metastatic sites. From the time of metastasis until death or the end of observation (12/2010): type and duration of antihormonal therapy, number and duration of palliative therapy lines, type and duration of chemotherapy, type and duration of anti-HER2-therapy (trastuzumab-mono, aromatase-inhibitor + trastuzumab, chemotherapy + trastuzumab, lapatinib-mono, capecitabine + lapatinib, sequential trastuzumab + lapatinib), number of trastuzumab-containing therapy lines, first therapy line containing trastuzumab, trastuzumab/chemotherapy combinations used, bisphosphonate therapy, radiotherapy, type of local therapy of brain metastases, cardiac function under trastuzumab, duration and cause of hospitalization (tumour, comorbidity, therapy), cause of death, place of death. Overall survival was defined as the time between initial diagnosis of metastasis and death or the end of observation (12/2010). Survival analyses 
were performed according to the method of Kaplan and Meier using SPSS 19. Descriptive analyses (frequencies), medians and means were computed in SPSS as well, mean differences were tested for statistical significance by analyses of variance (ANOVA) or by independent samples t-tests.

\section{Results}

One hundred and eighteen consecutive patients with complete data sets were evaluated. Patient characteristics are depicted in Table 1.

Table 1. Patient and tumour characteristics

\begin{tabular}{|c|c|c|}
\hline $\begin{array}{c}\text { Median age at initial diagnosis of metastasis }(\mathbf{n}=\mathbf{1 1 8}) \\
\text { - } \quad 58 \text { years }(33-92)\end{array}$ & & \\
\hline \multicolumn{3}{|c|}{ Menopausal status at the time of initial diagnosis of breast cancer $(n=118)$} \\
\hline - $\quad$ remenopausal & $n=46$ & $39 \%$ \\
\hline - postmenopausal & $n=72$ & $61 \%$ \\
\hline \multicolumn{3}{|l|}{ Tumour grade (n=126; all tumours) } \\
\hline - $\quad$ grading $1(\mathrm{G} 1)$ & $n=4$ & $3 \%$ \\
\hline - $\quad$ grading $2(\mathrm{G} 2)$ & $n=36$ & $29 \%$ \\
\hline - $\quad$ grading $3(\mathrm{G} 3)$ & $n=74$ & $59 \%$ \\
\hline - $\quad$ grading $4(\mathrm{G} 4)$ & $n=2$ & $2 \%$ \\
\hline - $\quad$ grading not evaluable (GX) & $n=10$ & $8 \%$ \\
\hline \multicolumn{3}{|l|}{ Histological type (n=126; all tumours) } \\
\hline - ductal & $n=79$ & $63 \%$ \\
\hline - lobular & $n=16$ & $13 \%$ \\
\hline - other & $n=12$ & $15 \%$ \\
\hline - not evaluable & $n=19$ & $15 \%$ \\
\hline \multicolumn{3}{|l|}{ Hormone receptor status (n=126; all tumours) } \\
\hline $\begin{array}{l}\text { - oestrogen receptor positive / progesterone } \\
\text { receptor positive }(\mathrm{ER}+/ \mathrm{PR}+)\end{array}$ & $n=55$ & $44 \%$ \\
\hline $\begin{array}{l}\text { - oestrogen receptor positive / progesterone } \\
\text { receptor negative }(\mathrm{ER}+/ \mathrm{PR}-)\end{array}$ & $n=16$ & $13 \%$ \\
\hline $\begin{array}{l}\text { - oestrogen receptor negative / progesterone } \\
\text { receptor positive }(\mathrm{ER}-/ \mathrm{PR}+)\end{array}$ & $n=5$ & $4 \%$ \\
\hline $\begin{array}{l}\text { - oestrogen receptor negative / progesterone } \\
\text { receptor negative }(\mathrm{ER}-/ \mathrm{PR}-)\end{array}$ & $n=38$ & $30 \%$ \\
\hline - receptor status not evaluable & $n=12$ & $10 \%$ \\
\hline \multicolumn{3}{|c|}{ Metastatic status at the time of initial diagnosis of breast cancer $(n=118)$} \\
\hline - $\quad$ no distant metastases (M0) & $n=89$ & $75 \%$ \\
\hline - $\quad$ distant metastases (M1) & $n=26$ & $22 \%$ \\
\hline - $\quad$ metastatic status not evaluable (MX) & $n=3$ & $3 \%$ \\
\hline \multicolumn{3}{|l|}{ Median Disease Free Survival [DFS] $(\mathrm{n}=118)$} \\
\hline \multicolumn{3}{|l|}{22 months $(0-362)$} \\
\hline \multicolumn{3}{|l|}{ Number of metastatic sites at initial diagnosis of metastasis $(n=118)$} \\
\hline - $\quad$ mean $+/$ - standard deviation & $1.4+/-0.72$ & \\
\hline - $\quad$ median (range) & $1(1-4)$ & \\
\hline \multicolumn{3}{|c|}{ Organ site involvement at initial diagnosis of metastasis [multiple responses possible] $(\mathrm{n}=118)$} \\
\hline - bone & $n=43$ & $36 \%$ \\
\hline - liver & $n=43$ & $36 \%$ \\
\hline - $\quad$ lung & $n=29$ & $25 \%$ \\
\hline - $\quad$ lymph nodes & $n=20$ & $17 \%$ \\
\hline - $\quad$ pleura & $n=8$ & $7 \%$ \\
\hline
\end{tabular}




\begin{tabular}{|c|c|c|c|}
\hline & $\begin{array}{ll}\text { - } & \text { skin } \\
\text { - } & \text { brain } \\
\text { - } & \text { other }\end{array}$ & $\begin{array}{l}n=6 \\
n=5 \\
n=12\end{array}$ & $\begin{array}{l}5 \% \\
4 \% \\
10 \%\end{array}$ \\
\hline \multicolumn{4}{|c|}{ Adjuvant therapy $(n=118)$} \\
\hline & $\begin{array}{l}\text { - chemotherapy }+ \text { antihormonal therapy or } \\
\text { chemotherapy }+ \text { antihormonal therapy }+ \\
\text { radiotherapy }\end{array}$ & $n=36$ & $31 \%$ \\
\hline & $\begin{array}{l}\text { - chemotherapy or } \\
\text { chemotherapy }+ \text { radiotherapy }\end{array}$ & $n=25$ & $21 \%$ \\
\hline & - radiotherapy & $n=13$ & $11 \%$ \\
\hline & $\begin{array}{l}\text { - antihormonal therapy or } \\
\text { antihormonal therapy }+ \text { radiotherapy }\end{array}$ & $n=9$ & $8 \%$ \\
\hline & no adjuvant therapy & $n=35$ & $30 \%$ \\
\hline
\end{tabular}

Twenty-two percent of patients were metastasized at the time of first breast cancer diagnosis. The median disease free survival [DFS] was 22 months (0-362), defined as time between initial diagnosis and diagnosis of metastasis. Three percent received trastuzumab in addition to their adjuvant therapy.

\subsection{Palliative Systemic Therapy}

Seventy-eight percent of patients with hormone receptor positivity received antihormonal therapy $(\mathrm{n}=62)$ using an aromatase inhibitor in the majority of cases $(n=50 ; 81 \%)$. Ninety percent of patients $(n=106)$ received chemotherapy with a median of 3 chemotherapy lines (0-13).

Seventy-five percent $(n=89)$ received anti-HER2-therapy consisting of trastuzumab in $80 \%$, lapatinib in $1 \%$ and sequential trastuzumab + lapatinib therapy in $19 \%$. Twenty-five percent $(n=29)$ received no targeted anti-HER2-therapy. $2 \%(n=2)$ had no palliative treatment and $23 \%(n=27)$ received no trastuzumab. A median of 1 trastuzumab-containing line (0-8) was applied to all patients. Trastuzumab was applied as monotherapy in $37 \%$ (10\% maintenance therapy) and in combination therapy in $63 \%$ of trastuzumab containing therapies. Trastuzumab containing therapy lines and trastuzumab combination partners are shown in Table 2.

Table 2. Palliative trastuzumab therapy

\begin{tabular}{|c|c|c|}
\hline \multicolumn{3}{|l|}{ Palliative therapy lines containing trastuzumab $(n=88)$} \\
\hline - $\quad 1^{\text {st }}$ line & $n=33$ & $38 \%$ \\
\hline - $\quad 2^{\text {nd }}$ line & $n=24$ & $27 \%$ \\
\hline - $\quad 3^{\text {rd }}$ line & $n=10$ & $11 \%$ \\
\hline - $4^{\text {th }}$ line & $n=14$ & $16 \%$ \\
\hline - $5^{\text {th }}$ line & $n=5$ & $6 \%$ \\
\hline - $6^{\text {th }}$ line & $n=2$ & $2 \%$ \\
\hline \multicolumn{3}{|l|}{ Palliative therapies containing trastuzumab $(n=217)$} \\
\hline - Trastuzumab: mono or maintenance & $n=81$ & $37 \%$ \\
\hline - $\quad$ Paclitaxel + Trastuzumab & $n=39$ & $18 \%$ \\
\hline - $\quad$ Vinorelbin + Trastuzumab & $n=36$ & $17 \%$ \\
\hline - $\quad$ Capecitabine + Trastuzumab & $n=17$ & $8 \%$ \\
\hline - $\quad$ Docetaxel + Trastuzumab & $n=15$ & $7 \%$ \\
\hline - Gemcitabine + Trastuzumab & $n=12$ & $6 \%$ \\
\hline - $\quad$ Docetaxel + Carboplatin + Trastuzumab & $n=5$ & $2 \%$ \\
\hline - $\quad$ Lapatinib + Trastuzumab & $n=2$ & $1 \%$ \\
\hline - $\quad$ Lapatinib + Capecitabine + Trastuzumab & $n=2$ & $1 \%$ \\
\hline - $\quad$ Other + Trastuzumab & $n=8$ & $4 \%$ \\
\hline
\end{tabular}


Fifty percent of patients developed bone metastases in the course of the disease, $93 \%$ of them received bisphosphonates.

\subsection{Palliative Therapy of Brain Metastases}

Five percent of patients showed CNS involvement (primary brain metastases) at initial diagnosis of metastatic disease, $35 \%$ developed brain metastases during the course of their disease. Twenty percent of these patients showed at initial diagnosis of brain metastases a single metastasis, $71 \%$ showed two or more metastases and in $10 \%$ the number of metastases was not retrievable. Local therapy consisted of whole brain radiotherapy in $63 \%$, operation plus whole brain radiotherapy in $17 \%$, operation only in $7 \%$ and no local therapy in $12 \%$. Twenty-seven percent of the patients who developed brain metastases received lapatinib treatment.

\subsection{Hospitalisation and Place of Death}

Eighty-three percent of patients had to be hospitalized during the course of treatment. Median number of hospitalizations per patient was $2(0-11)$ and the median duration of hospital stay was 8 days (0-79). Causes for hospitalization were induced by the tumour in $67 \%$, comorbidity in $18 \%$, rehabilitation in $13 \%$ and side effects of the therapy in $2 \%$. Seventy-nine percent of the patients have died, $86 \%$ of these died due to tumour progression and $5 \%$ due to other causes. In $9 \%$ the cause of death could not be determined. Forty-eight percent of patients could die at home, $35 \%$ died in hospital, $3 \%$ in an old pensioner's home and $3 \%$ in hospice care. In $10 \%$ the place of death could not be determined.

\subsection{Survival}

Median overall survival since initial diagnosis of metastasis was 34 months $(0-277+)$ (Figure 1$)$. The probability of $1,3,5$, and 10 year survival was $85 \%, 47 \%, 25 \%$ and $9 \%$ respectively.

The presence of CNS metastases at initial diagnosis and a disease free interval less than 2 years were correlated significantly with poor survival (Figure 2 and Figure 3). Univariate analysis showed no significant correlation between different metastatic sites at initial diagnosis, primary metastatic disease, hormone receptor status or anti-Her2-therapy.

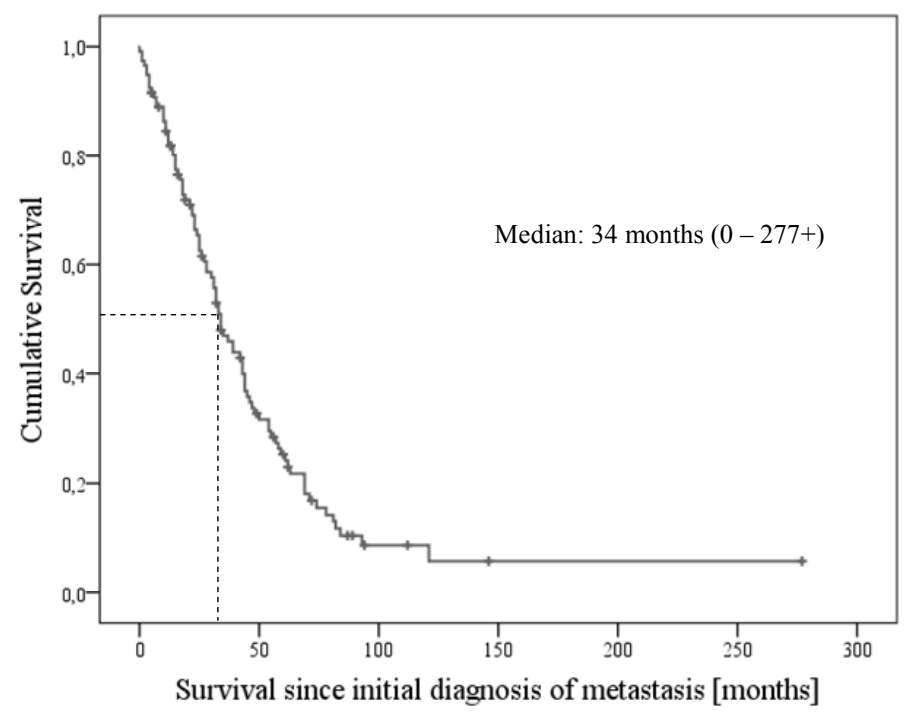

Figure 1. Survival since initial diagnosis of metastasis in months $(\mathrm{n}=118)$ 


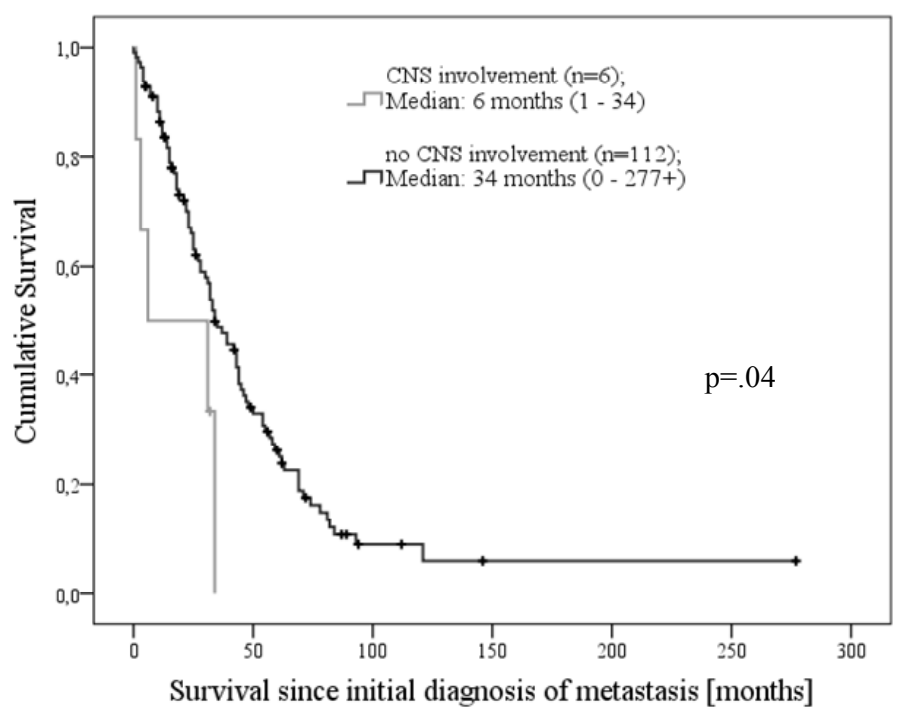

Figure 2. Correlation of survival rates and the presence of CNS metastases at initial diagnosis

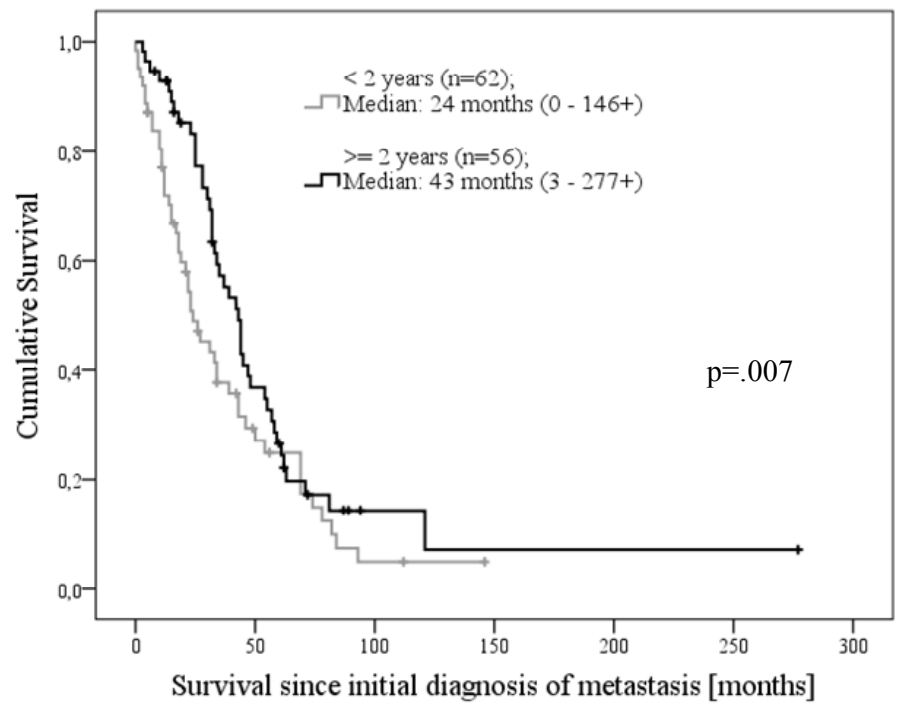

Figure 3. Correlation of survival rates and disease free intervals of more or less than 2 years

Twenty-seven patients with bone metastases only at diagnosis showed a median survival of 39 months, compared to 30 months of 68 patients with visceral metastases. The shortest median survival of 6 months was seen in 6 patients presenting with brain metastases at diagnosis.

Patients with a positive hormone receptor had a median survival of 39 months compared to 27 months in patients who had hormone receptor negative tumours $(\mathrm{p}=0.121)$. These differences were not statistically significant probably due to low patient numbers.

Table 3 shows characteristics of patients receiving anti-Her2-therapy versus patients receiving no anti-Her2-therapy. The comparison of these groups shows that patients without anti-Her2-therapy fell into a better prognostic subgroup, due to a higher percentage of hormone receptor expression, a lower rate of brain metastases, a lower rate receiving chemotherapy, a higher rate of antihormonal therapy and no palliative therapy at all! Median overall survival was 34 months in patients with anti-Her2-therapy compared to 30 months in patients without anti-Her2-therapy although not statistically significant! 
Table 3. Palliative trastuzumab therapy

\begin{tabular}{rll}
\hline & $\begin{array}{l}\text { anti-Her2-therapy } \\
(\mathbf{n = 8 9})\end{array}$ & $\begin{array}{l}\text { no } \\
\text { anti-Her2-therapy } \\
(\mathbf{n}=\mathbf{2 9})\end{array}$ \\
\hline Time of diagnosis of metastasis & & \\
- $1995-1999$ & $24 \%$ & $24 \%$ \\
- $2000-2004$ & $48 \%$ & $48 \%$ \\
- $2005-2010$ & $28 \%$ & $28 \%$
\end{tabular}

Age at diagnosis of metastatic disease
- median (range)
$58(33-92)$
$63(39-89)$

Disease free interval in months

- median (range)

$22(0-362)$

$22(0-247)$

Menopausal status at initial diagnosis of metastasis

- premenopausal

$29 \%$

$21 \%$

$79 \%$

Hormone receptor status: positive
- frequencies
$61 \%$
$90 \%$

Number of metastatic sites in the course of the disease

- 1 site

$26 \%$

$38 \%$

- 2 sites

$29 \%$

$41 \%$

- 3 sites

$22 \%$

$21 \%$

- more than 3 sites

$22 \%$

$0 \%$

Metastatic sites in the course of the disease

- $\mathrm{CNS}$

$43 \%$

$17 \%$

- visceral

$45 \%$

$45 \%$

- lymph nodes

$4 \%$

$17 \%$

- bone only

$21 \%$

- other

$6 \%$

$0 \%$

Taxane-containing therapies in the course of the disease

$$
\text { - frequencies }
$$

$75 \%$

$31 \%$

Number of palliative therapy lines

- median (range)

$5(1-13)$

$2(1-8)$

Palliative therapies

- chemotherapy+antihormonal therapy or chemotherapy+antihormonal therapy+radiotherapy

- chemotherapy or chemotherapy + radiotherapy

- antihormonal therapy or

antihormonal therapy + radiotherapy

- others

- no palliative treatment

$\begin{array}{ll}47 \% & 55 \% \\ 49 \% & 14 \% \\ 2 \% & 21 \% \\ 1 \% & 3 \% \\ 0 \% & 7 \%\end{array}$

Cumulative duration of hospitalizations in days

- median (range)

$19(0-153)$

$13(0-154)$

Causes of hospitalizations per patient

$\begin{array}{ll}\text { - } & \text { tumour } \\ \text { - } & \text { side effects of the treatment }\end{array}$

Deaths until the end of observation

Causes of death

- frequencies

- tumour

- others

Places of death

- at home

- hospital

- others

$\begin{array}{ll}74 \% & 59 \% \\ 4 \% & 3 \%\end{array}$

$82 \%$

$69 \%$

$88 \%$

$80 \%$

$12 \%$

$20 \%$

$51 \%$

$40 \%$

$40 \%$

$20 \%$ 


\section{Discussion}

HER2-overexpression confers a negative prognosis with an increased relapse rate and reduced overall survival in primary breast cancer. Due to the aggressiveness of the tumour, HER2-positive metastatic breast cancer has a significantly shorter median Overall Survival (OS) of 18-20 months compared to HER2-negative disease with a median survival of 24-30 months (Slamon et al., 1987; Smith, 2001; Slamon et al., 2001; Marty et al., 2005). OS has been shown to increase slowly over the years in metastatic breast cancer in prospective studies and in routine care (Gennari, Conte, Rosso, Orlandini, \& Bruzzi, 2005; Giordano et al., 2004; Weide et al., 2009). The addition of trastuzumab to anthracycline- or paclitaxel-based first line chemotherapy has improved median OS from 20.3 to 25.1 months (Slamon et al., 2001). A retrospective study has shown that early application of trastuzumab in HER2-positive metastatic breast cancer achieves the same OS as standard therapy in HER2-negative disease (Dawood, Broglio, Buzdar, Hortobagyi, \& Giordano, 2009). The difference in prognosis is equalized through the use of trastuzumab (Dawood et al., 2009). The small molecule Lapatinib has the advantage that it has also shown efficacy in brain metastases which developed during trastuzumab therapy (Lin et al., 2008).

The above mentioned studies have shown an improvement of overall survival in HER2-metastatic breast cancer, when trastuzumab is added. It is known that less than $2 \%$ of patients with metastatic breast cancer older than 60 years are treated in prospective clinical trials (American College of Physicians, 1999). No data are available that report the percentage of patients with metastatic breast cancer in Germany who receive part of their treatment in prospective clinical trials. In our own group practice only $10 \%$ of all patients with metastatic breast cancer are treated in prospective clinical trials due to different reasons (inclusion and exclusion criteria, lack of studies, patient preferences etc). Therefore the impact of anti-HER2-therapy on the majority of patients treated outside clinical trials is not known. In our retrospective study we have observed a prolonged OS of 34 months since initial diagnosis of metastasis in HER2-positive metastatic breast cancer in patients who were treated outside clinical trials in routine care. $75 \%$ of patients received trastuzumab therapy as monotherapy or with different chemotherapy partners as combination therapy. Trastuzumab monotherapy has shown efficacy in the first line and in further lines of therapy (Baselga et al., 1996; Cobleigh et al., 1999; Vogel et al., 2002). In hormone receptor positive disease it can effectively be combined with an aromatase inhibitor (Kaufmann et al., 2009). This chemotherapy-free strategy is particularly beneficial for patients who refuse chemotherapy or who have a reduced performance score. In combination therapy it has been shown that different chemotherapeutics like platinum derivatives, taxanes and vinorelbine act synergistically with trastuzumab (Geyer et al., 2006; Pegram et al., 1999; Pietras et al., 1994). Even if the tumour progresses, there is evidence that it is reasonable to continue with trastuzumab while changing the chemotherapeutic partner. This so called treatment beyond progression has shown a prolonged progression free interval compared with a trastuzumab free therapy (von Minckwitz et al., 2009). Concerning lapatinib, $14 \%$ of our patients were treated with lapatinib + chemotherapy after trastuzumab due to tumour progression. Especially the combination of lapatinib plus capecitabine has shown efficacy in HER2-positive disease which progresses during trastuzumab treatment (Geyer et al., 2006). Five percent of our patients presented with CNS involvement at initial diagnosis and 35\% developed brain metastases during the course of their disease. Treatment consisted mainly of whole brain radiotherapy (WBR) in 63\% and operation plus WBR in $17 \%$. The approval of lapatinib for the treatment of brain metastases in HER2-positive breast cancer has improved treatment options in this difficult clinical situation (Lin et al., 2008). Twenty-seven percent of our patients with brain metastases received therapy with lapatinib. Compared to historical controls we have observed an improved median survival of 34 months in our routine care patient cohort, despite the fact that only $75 \%$ of the patients received an anti-HER2-targeted therapy. The comparison between patients receiving anti-HER2-therapy and those not receiving this therapy disclosed that patients without anti-HER2-therapy fell into a favourable prognostic group due to a different tumour biology with a lower incidence of CNS involvement, a lower number of metastatic sites in the course of the disease, lower number of palliative lines, lower percentage of patients receiving chemotherapy a higher rate of antihormonal therapy only and a higher rate of no cytoreductive therapy at all (Table 3). Despite less intensive therapy, these patients showed no statistically significant difference in survival (34 versus 30 months). We would like to speculate that if these patients would have received anti-HER2-therapy, the treatment results could have been further improved. Another way of further improving treatment results is looking at the percentage of patients receiving anti-HER2-therapy as part of their first line treatment. Only $28 \%$ of our patients received trastuzumab therapy as part of their first line treatment. We would like to speculate that if targeted therapy against HER2 is part of first line treatment, outcome could be improved even further. In summary our data show that anti-HER2-therapy leads to a prolongation of life with a median overall survival of 34 months compared to historical data which have reported a median overall survival of 18-20 months without anti-HER2-therapy (Smith et al., 2001; Slamon et al., 2001). In our own patient cohort of 632 patients with metastatic breast cancer treated in our group practice between 
1995-2010 no difference in overall survival could be detected between HER2-negative and HER2-positive patients (Weide et al., 2012c). These observations are in line with data from another institution (Dawood et al., 2009).

Future strategies include the combination of trastuzumab plus lapatinib which has shown superiority over lapatinib in trastuzumab refractory disease (Blackwell et al., 2010). New monoclonal antibodies like pertuzumab, which inhibits HER2-dimerization more effectively and acts synergistically with trastuzumab hold promise (Baselga et al., 2010). Recently data have been presented showing a marked improvement in progression free survival from 12.4 to 18.5 months when trastuzumab and pertuzumab are applied together with docetaxel compared to trastuzumab+docetaxel alone as first line therapy in HER2-positive metastatic breast cancer (Baselga et al., 2011).

Another approach is TDM-1, where the microtubulus-inhibiting drug maytensin is linked to trastuzumab. Upon binding to HER2, TDM-1 is internalized in the cell, maytensin is released and cell killing is achieved by microtubulus inhibition. TDM-1 has shown to be highly active in trastuzumab refractory breast cancer patients (Burris et al., 2011). The development of more potent tyrosine kinase inhibitors might improve specificity and the magnitude of HER2-positive cell killing.

Apart from anti-HER2-therapy we think that the human factor plays a major part in the care of patients with metastatic breast cancer concerning longevity and quality of life. A number of studies have shown that a good psychosocial support not only achieves a better life but also a longer life in metastatic breast cancer and other solid tumors (Spiegel, 2012). We think that the fighting spirit between the patient and her oncologist and the supporting network of the oncology team, relatives, friends, general practitioners, gynaecologists, psychologists, social workers and clergy are a solid basis to reduce psychosocial distress, maintain quality of life and achieve longevity in patients with metastatic breast cancer who receive their treatment in an oncology group practice (Mergenthaler et al., 2011; Weide et al., 2012a; Feiten et al., 2011; Weide et al., 2012b).

\section{References}

American College of Physicians. (1999). Oncology Medical Knowledge Self-Assessment Program. Philadelphia, American College of Physicians: www.acponline.org

Baselga, J., Gelmon, K. A., Verma, S., Wardley, A., Conte, P., Miles, D., ... Gianni, L. (2010). Phase II trial of pertuzumab and trastuzumab in patients with human epidermal growth factor receptor 2-positive metastatic breast cancer that progressed during prior trastuzumab therapy. J Clin Oncol, 28, 1128-1144. http://dx.doi.org/10.1200/JCO.2009.24.2024

Baselga, J., Kim, S.-B., Im, S.-A., Hegg, R., Im, Y.-H., Roman, L., ... Swain, S. M. (2011). A Phase III, Randomized, Double Blind, Placebo-Controlled Registration Trial to evaluate the efficacy and safety of Pertuzumab+Trastuzumab+Docetaxel vs. Placebo+Trastuzumab+Docetaxel in patients with previously untreated Her2-positive metastatic breast cancer (CLEOPATRA). Cancer Res, 71(24 Supplement), S5-5.

Baselga, J., Tripathy, D., Mendelsohn, J., Baughman, S., Benz, C. C., Dantis, L., ... Norton, L. (1996). Phase II study of weekly intravenous recombinant humanized anti-p $185^{\mathrm{HER} 2}$ monoclonal antibody in patients with HER2/neu-overexpressing metastatic breast cancer. J Clin Oncol, 14, 737-744.

Blackwell, K. L., Burstein, H. J., Storniolo, A. M., Rugo, H., Sledge, G., Koehler, M., ... O’Shaughnessy, J. (2010). Randomized study of lapatinib alone or in combination with trastuzumab in women with ErbB2-positive, trastuzumab-refractory metastatic breast cancer. J Clin Oncol, 28(7), 1124-1130. http://dx.doi.org/10.1200/JCO.2008.21.4437

Burris, H. A., Rugo, H. S., Vukelja, S. J., Vogel, C. L., Borson, R. A., Limentani, S., ... O’Shaughnessy, J. A. (2011). Phase II study of the antibody conjugate trastuzumab-DM1 for the treatment of human epidermal growth factor receptor 2 (HER2)-positive breast cancer after prior HER2-directed therapy. J Clin Oncol, 29(4), 398-405. http://dx.doi.org/10.1200/JCO.2010.29.5865

Clynes, R. A., Towers, T. L., Presta, L. G., \& Ravetch, J. V. (2000). Inhibitory Fe receptors modulate in vivo cytotoxicity against tumor targets. Nat Med, 6(4), 443-446.

Cobleigh, M. A., Vogel, C. L., Tripathy, D., Robert, N. J., Scholl, S., Fehrenbacher, L., ... Slamon, D. J. (1999). Multinational study of the efficacy and safety of humanized anti-HER2 monoclonal antibody in women who have HER2-overexpressing metastatic breast cancer that has progressed after chemotherapy for metastatic disease. J Clin Oncol, 17, 2639-2648.

Dawood, S., Broglio, K., Buzdar, A. U., Hortobagyi, N., \& Giordano, S. (2009). Prognosis of women with 
metastatic breast cancer by HER2 status and trastuzumab treatment: an institutional-based review. $J$ Clin Oncol, 28, 92-98. http://dx.doi.org/10.1200/JCO.2008.19.9844

Dendukuri, N., Khetani, K., McIsaac, M., \& Brophy, J. (2007). Testing for HER2-positive breast cancer: a systematic review and cost-effectiveness analysis. CMAJ, 176(10), 1429-1434. http://dx.doi.org/10.1503/cmaj.061011

Feiten, S., Friesenhahn, V., Heymanns, J., Kleboth, K., Köppler, H., Mergenthaler, U., ... Weide, R. (2011) Evaluation of psychosocial distress in main care-givers of patients with a metastatic solid tumor who receive treatment in a community based oncology group practice. Onkologie, 34(S6), V401

Gennari, A., Conte, P., Rosso, R., Orlandini, C., \& Bruzzi, P. (2005). Survival of metastatic breast carcinoma patients over a 20-year period. Cancer, 104, 1742-1750. http://dx.doi.org/10.1002/cncr.21359

Geyer, C. E., Forster, J., Lindquist, D., Chan, S., Romieu, G., Pienkowski, T., ... Cameron, D. (2006). Lapatinib plus capecitabine for HER2-positive advanced breast cancer. $N$ Engl $J$ Med, 355, 2733-2743. http://dx.doi.org/10.1056/NEJMoa064320

Giordano, S. H., Buzdar, A. U., Smith, T. L., Kau, S. W., Yang, Y., \& Hortobagyi, G. N. (2004). Is breast cancer survival improving? Cancer, 100, 44-52. http://dx.doi.org/10.1002/cncr.11859

Hudis, C. A. (2007). Trastuzumab - mechanism of action and use in clinical practice. $N$ Engl J Med, 357(1), 39-51. http://dx.doi.org/10.1056/NEJMra043186

Kaufmann, B., Mackey, J. R., Clemens, M. R., Bapsy, P. P., Vaid, A., Wardley, A., ... Jones, A. (2009). Trastuzumab plus anastrozole versus anastrozole alone for the treatment of postmenopausal women with human epidermal growth factor receptor 2-positive, hormone receptor-positive metastatic breast cancer: results from the randomized phase III TAnDEM study. $J$ Clin Oncol, 27(33), 5529-5537. http://dx.doi.org/10.1200/JCO.2008.20.6847

Lin, N., Carey, L. A., Liu, M. C., Younger, J., Come, S. E., Ewend, M., ... Winer, E. P. (2008). Phase II trial of lapatinib for brain metastases in patients with human epidermal growth factor receptor 2-positive breast cancer. J Clin Oncol, 26, 1993-1999. http://dx.doi.org/10.1200/JCO.2007.12.3588

Marty, M., Cognetti, F., Maraninchi, D., Snyder, R., Mauriac, L., Tubiana-Hulin, M., ... Extra, J. M. (2005). Randomized phase II trial of the efficacy and safety of trastuzumab combined with docetaxel in patients with human epidermal growth factor receptor 2-positive metastatic breast cancer administered as first line treatment: the M77001 study group. $J$ Clin Oncol, 23(19), 4265-4274. http://dx.doi.org/10.1200/JCO.2005.04.173

Mergenthaler, U., Heymanns, J., Köppler, H., Thomalla, J., van Roye, C., Schenk, J., \& Weide, R. (2011). Evaluation of psychosocial distress in patients treated in a community-based oncology group practice in Germany. Ann Oncol, 22(4), 931-938. http://dx.doi.org/10.1093/annonc/mdq455

Pegram, M. D., Hsu, S., Lewis, G., Pietras, R., Beryl, M., Sliwkowski, M., ... Slamon, D. (1999). Inhibitory effects of combinations of HER2-antibody and chemotherapeutic agents used for treatment of human breast cancers. Oncogene, 18(13), 2241-2251.

Pietras, R. J., Fendly, B. M., Chazin, V. R., Pegram, M. D., Howell, S. B., \& Slamon, D. J. (1994). Antibody to Her2/neu receptor blocks DNA repair after cisplatin in human breast cancer and ovarian cancer cells. Oncogene, 9(7), 1829-1838.

Slamon, D. J., Clark, G. M., Wong, S. G., Levin, W. J., Ullrich, A., \& McGuire, W. L. (1987). Human breast cancer: Correlation of relapse and survival with amplification of the HER-2/neu oncogene. Science, 235, 177-182. http://dx.doi.org/10.1126/science.3798106

Slamon, D. J., Leyland-Jones, B., Shak, S., Fuchs, H., Paton, V., Bajamonde, A., ... Norton, L. (2001). Use of chemotherapy plus a monoclonal antibody against HER2 for metastatic breast cancer that overexpresses HER2. $N$ Engl J Med, 344, 783-792. http://dx.doi.org/10.1056/NEJM200103153441101

Smith, I. E. (2001). Efficacy and safety of Herceptin in women with metastatic breast cancer: results from $\begin{array}{lllll}\text { pivotal clinical studies. Anticancer Drugs, } & \text { 12(Suppl 4), }\end{array}$ http://dx.doi.org/10.1097/00001813-200112004-00002

Spiegel, D. (2012). Mind matters in cancer survival. Psycho-Oncology, 21, 588-593. http://dx.doi.org/10.1002/pon.3067

Vogel, C. L., Cobleigh, M. A., Tripathy, D., Gutheil, J. C., Harris, L. N., Fehrenbacher, L., ... Press, M. (2002). 
Efficacy and safety of trastuzumab as single agent in first-line treatment of HER2-overexpressing metastatic breast cancer. J Clin Oncol, 20, 719-726. http://dx.doi.org/10.1200/JCO.20.3.719

von Minckwitz, G., du Bois, A., Schmidt, M., Maass, N., Cufer, T., de Jongh, F. E., ... Loibl, S. (2009). Trastuzumab beyond progression in human epidermal growth factor receptor 2-positive advanced breast cancer: A German Breast Group 26 / Breast international Group 03-05 study. J Clin Oncol, 27(12), 1999-2006. http://dx.doi.org/10.1200/JCO.2008.19.6618

Weide, R., Feiten, S., Friesenhahn, V., Heymanns, J., Kleboth, K., Mergenthaler, U., ... Köppler, H. (2012a). Identifying Caregivers and Their Meaning for Patients with Metastatic Solid Tumours in Routine Care: A Survey at a Communitiy-Based Oncology Group Practice in Germany. Cancer and Clinical Oncology, 1(1), 41-51. http://dx.doi.org/10.5539/cco.v1n1p41

Weide, R., Feiten, S., Friesenhahn, V., Heymanns, J., Kleboth, K., Mergenthaler, U., ... Köppler, H. (2012b). Patients with metastatic solid tumors who receive their treatment in a community based oncology group practice live longer. Journal of Cancer Research and Clinical Oncology, 138(S1), 144.

Weide, R., Mergenthaler, U., Pandorf, A., Arndt, H., Heymanns, J., Thomalla, T., \& Köppler, H. (2009). Improved survival of patients with metastatic breast cancer in routine care: results of a retrospective study in a community-based oncology group practice 1995-2005. Onkologie, 32, 107-113. http://dx.doi.org/10.1159/000197360

Weide, R., Feiten, S., Friesenhahn, V., Heymanns, J., Kleboth, K., Thomalla, J., ... Köppler, H. (2012c). Die Behandlung von Patientinnen mit metastasiertem Mammakarzinom in einer onkologischen Schwerpunktpraxis führt zu einem deutlich längeren Gesamtüberleben im Vergleich mit Registerdaten. Senologie - Zeitschrift für Mammadiagnostik und -therapie, 9, A175. http://dx.doi.org/10.1055/s-0032-1313541 